\title{
Mutual Separation of Palladium (II) and Platinum (IV) from Hydrochloric Acid Solutions Using $m$-Phenylene Diamine-Containing Agents
}

\author{
Kazuya Matsumoto*, Sumito YamakawA*, Tatsuya AoYagl*, Kazutoshi HagA*, \\ Mitsutoshi JIKEI* and Atsushi SHIBAYAMA** \\ * Department of Materials Science, Graduate School of Engineering Science, \\ Akita University, 1-1 Tegatagakuen-machi, Akita-shi, Akita 010-8502, Japan \\ ** Department of Earth Resource Engineering and Environmental Science, \\ Graduate School of International Resource Science, \\ Akita University, 1-1 Tegatagakuen-machi, Akita-shi, Akita 010-8502, Japan \\ E-mail :kmatsu@gipc.akita-u.ac.jp
}

\begin{abstract}
$m$-Phenylene diamine-containing compounds were synthesized via a one-pot process and subsequently used as new precipitating agents (PA1 and PA2). The precipitation of Pd and Pt was studied using PA1 and PA2 as metal precipitants. While PA1 exclusively precipitated $\mathrm{Pd}$ from a $\mathrm{HCl}$ solution containing $\mathrm{Pd}, \mathrm{Pt}$, and base metals, PA2 achieved precipitation of both Pd and Pt from the metal-containing $\mathrm{HCl}$ solution. Mutual separation of Pd and Pt was achieved by using PA1 and PA2 in the first and second precipitation steps, respectively. Separation tests at varying agent loadings revealed that $\mathrm{Pd}$ and $\mathrm{Pt}$ were precipitated by forming of an ion-pair composed of a metal chloro-complex anion (i.e., $\left[\mathrm{PdCl}_{4}\right]^{2-}$ or $\left[\mathrm{PtCl}_{6}\right]^{2-}$ ) and one precipitating agent molecule (i.e., divalent cation). The stoichiometric ratio of the ion-pairs was in agreement with the atomic ratios estimated from X-ray photoelectron spectroscopy results. Since the precipitation mechanism herein was based on the formation of an ion-pair, the cations of the precipitating agents only recovered Pd and Pt chloro-complex anions when the cations of the base metals were present in the solution. The different hydrophobicities of the precipitating agents enabled mutual separation of Pd and Pt.
\end{abstract}

Keywords : platinum group metals / metal precipitate / mutual separation / precipitating agent

\section{INTRODUCTION}

Platinum group metals (PGMs), especially Pd and Pt, are important industrial elements owing to their extensive use in electrical devices, dental materials, catalysts, and jewelry $[1,2]$. Given the scarcity of the PGMs primary resources, the recycling of these metals from secondary sources or post-consumer scrap is essential [3]. Solvent extraction is regarded as a typical and practical method to recover PGM ions [4-8]. For example, Pd(II) and $\mathrm{Pt}(\mathrm{IV})$ can be extracted from hydrochloric acid $(\mathrm{HCl})$ solutions with di- $n$-octyl sulfide [9] and tri- $n$-butyl phosphate [10] extractant agents, respectively. However, the use of volatile organic solvents as extractant diluents negatively affects the recovery process owing to their toxicity and environmental load.

Mutual separation of PGMs, which is required in the recovery process, is complicated because of the similar physical and chemical properties of the metal components. PGM ions are known to be recovered via coordination or ion-pair mechanisms [11]. Pd and $\mathrm{Pt}$ are typically recovered following a coordination mechanism with the trend $\mathrm{Pd}(\mathrm{II})>\mathrm{Pt}(\mathrm{IV})$ [12]. On the other hand, Pd and Pt chloro-complex anions (i.e., $\left[\mathrm{PdCl}_{4}\right]^{2-}$ and $\left[\mathrm{PtCl}_{6}\right]^{2-}$ ) were extracted to a similar extent via an ion-pair mechanism $[11,13]$. Therefore, mutual separation of $\mathrm{Pd}$ and $\mathrm{Pt}$ is generally performed by combining coordination and ion-pair recovery strategies, respectively. However, the utilization of different mechanisms within the recovery process requires several recovery agents specially designed for the corresponding recovery mechanism. In addition, the recovery of PGMs via a coordination mechanism is typically accompanied with base metals such as $\mathrm{Cu}, \mathrm{Fe}, \mathrm{Al}$, and $\mathrm{Zn}$ [12].

In this study, we report on the selective precipitation and mutual separation of Pd and Pt using new precipitating agents (i.e., $m$-phenylene diamine-containing compounds). These precipitating agents were prepared by condensation of aniline or 4-phenoxyaniline with 3,5-bis(trifluoroacetamido)benzoyl chloride followed by deprotection with hydrazine. The precipitation behaviors of Pd and $\mathrm{Pt}$ with the as-prepared precipitating agents were examined by using Pd- and Pt-containing $\mathrm{HCl}$ solutions with or without base metals. The precipitating agents prepared in this study enabled mutual separation of $\mathrm{Pd}$ and $\mathrm{Pt}$ from a $\mathrm{HCl}$ solution containing base metals via an ion-pair mechanism.

\section{EXPERIMENTAL}

\subsection{Materials}

$\mathrm{N}, \mathrm{N}$-Dimethylacetamide (DMAc) was purchased from Wako Pure Chemical Industries Ltd. and distilled from calcium hydride 
before use. Thionyl chloride, iron (II) chloride tetrahydrate, copper (II) acetate, and zinc power were purchased from Kanto Chemical Co., Inc., and used as received. 4-Phenoxyaniline and aluminum (III) chloride were purchased from Tokyo Kasei Kogyo Co., Ltd. and used as received. 3,5-Bis(trifluoroacetamido)benzoic acid was prepared following methods reported in the literature [14]. $\mathrm{Pd}(\mathrm{II})$ and $\mathrm{Pt}(\mathrm{IV})$ standard solutions (1000 ppm in $1 \mathrm{M} \mathrm{HCl}$ ) were purchased from Wako Pure Chemical Industries, Ltd. The $\mathrm{HCl}$ solution containing base metals was prepared by dissolving copper (II) acetate, iron (II) chloride tetrahydrate, aluminum (III) chloride, and zinc power in $\mathrm{HCl}$.

\subsection{Synthesis of precipitating agent 1 (PA1)}

3,5-Bis(trifluoroacetamido)benzoic acid $(2.20 \mathrm{~g}, 6.39 \mathrm{mmol})$ was refluxed in thionyl chloride $(25 \mathrm{~mL})$ for $2 \mathrm{~h}$. After the removal of thionyl chloride by distillation, chloroform was added and subsequently distilled off to ensure complete removal of thionyl chloride. The resulting product was dried under vacuum and subsequently dissolved in DMAc $(12 \mathrm{~mL})$. To the former solution, aniline $(0.54 \mathrm{~g}, 5.81 \mathrm{mmol})$ was added and the resulting mixture was stirred at room temperature for $12 \mathrm{~h}$ under nitrogen. After stirring at $50^{\circ} \mathrm{C}$ for a further $1 \mathrm{~h}$, water $(0.9 \mathrm{~mL})$ was added to the mixture and stirred at $50^{\circ} \mathrm{C}$ for another $1 \mathrm{~h}$. Hydrazine monohydrate $(5.5 \mathrm{~mL})$ was subsequently added and the mixture stirred at $50^{\circ} \mathrm{C}$ for $4 \mathrm{~h}$. The mixture was subsequently poured into a $5 \% \mathrm{NaHCO}_{3}$ aqueous solution. The resulting precipitate was collected by filtration, washed with water, and subsequently dried at $80^{\circ} \mathrm{C}$ for $12 \mathrm{~h}$ under vacuum. The yield was $1.18 \mathrm{~g}(88 \%) .{ }^{1} \mathrm{H}$ NMR (DMSO- $d_{6}, \delta$, ppm): $4.95(\mathrm{~s}, 4 \mathrm{H}), 6.01(\mathrm{~s}, 1 \mathrm{H}), 6.31(\mathrm{~d}$, $2 \mathrm{H}), 7.04$ (t, $1 \mathrm{H}), 7.31$ (t, $2 \mathrm{H}), 7.76(\mathrm{~d}, 2 \mathrm{H}), 9.94$ (s, $1 \mathrm{H}) .{ }^{13} \mathrm{C}$ NMR (DMSO- $\left.d_{6}, \delta, \mathrm{ppm}\right): 102.26,102.33,119.98,123.11,128.49$, 136.91, 139.62, 149.13, 167.32. Anal. Calcd. for $\left(\mathrm{C}_{13} \mathrm{H}_{13} \mathrm{~N}_{3} \mathrm{O}\right)$ : $\mathrm{C}$, 68.70; H, 5.77; N, 18.49; Found: C, 68.68; H, 5.89; N, 18.31.

\subsection{Synthesis of precipitating agent 2 (PA2)}

PA2 was synthesized in the same manner as PA1 although 4-phenoxyaniline was used instead of aniline. The yield was $88 \%$. ${ }^{1} \mathrm{H}$ NMR (DMSO- $d_{6}, \delta$, ppm): 4.95 (s, $\left.4 \mathrm{H}\right), 6.02$ (s, $\left.1 \mathrm{H}\right), 6.33$ (d, $2 \mathrm{H}), 6.98(\mathrm{~d}, 2 \mathrm{H}), 7.01(\mathrm{~d}, 2 \mathrm{H}), 7.10(\mathrm{t}, 1 \mathrm{H}), 7.37(\mathrm{t}, 2 \mathrm{H}), 7.78(\mathrm{~d}$, $2 \mathrm{H}), 9.99$ (s, $1 \mathrm{H}) .{ }^{13} \mathrm{C}$ NMR (DMSO- $\left.d_{6}, \delta, \mathrm{ppm}\right): 102.24,102.29$, 117.74, 119.32, 121.63, 122.87, 129.92, 135.59, 136.81, 149.12, 151.55, 157.48, 167.13. Anal. Calcd. for $\left(\mathrm{C}_{19} \mathrm{H}_{17} \mathrm{~N}_{3} \mathrm{O}_{2}\right): \mathrm{C}, 71.46 ; \mathrm{H}$, 5.37; N, 13.16; Found: C, 71.36; H, 5.34; N, 13.03.

\subsection{Precipitation procedure for $\mathrm{Pd}$ and $\mathrm{Pt}$}

To a $0.1 \mathrm{M} \mathrm{HCl}$ solution $(5 \mathrm{~mL}$ ) containing $\mathrm{Pd}(\mathrm{II})$ or $\mathrm{Pt}(\mathrm{IV})$ $(0.94 \mathrm{mmol} / \mathrm{L}$ for $\mathrm{Pd}$ and $0.51 \mathrm{mmol} / \mathrm{L}$ for Pt, i.e., $100 \mathrm{ppm}$ each) PA1 or PA2 were added and the mixture vigorously shaken at room temperature. The resulting solid was separated by centrifugation (7200 g, $10 \mathrm{~min})$ and the metal concentration in the supernatant was determined by inductively coupled plasma-atomic emission spectroscopy (ICP-AES). The metal separation experiments were carried out by varying the amount of precipitating agents and the shaking time.

\subsection{Separation of Pd and Pt from solutions containing base metals}

To a $0.1 \mathrm{M} \mathrm{HCl}$ solution $(5 \mathrm{~mL})$ containing $\mathrm{Pd}(\mathrm{II}), \mathrm{Pt}(\mathrm{IV})$, $\mathrm{Cu}(\mathrm{II}), \mathrm{Fe}(\mathrm{II}), \mathrm{Al}(\mathrm{III})$, and $\mathrm{Zn}$ (II) (50 ppm each) PA1 or PA2 (PA/ $\mathrm{Pd}=5 \mathrm{~mol} / \mathrm{mol}$, i.e., $23.5 \mu \mathrm{mol}$ each) were added and the mixture vigorously shaken for $3 \mathrm{~h}$ at room temperature. The resulting solid was separated by centrifugation $(7200 \mathrm{~g}, 10 \mathrm{~min})$ and the metal concentration in the supernatant was determined by ICP-AES.

\subsection{Mutual separation of $\mathrm{Pt}$ and $\mathrm{Pd}$}

PA1 $(5.3 \mathrm{mg}, 23.5 \mu \mathrm{mol})$ was added to a $0.1 \mathrm{M} \mathrm{HCl}$ solution $(10 \mathrm{~mL})$ containing $\mathrm{Pd}(\mathrm{II}), \mathrm{Pt}(\mathrm{IV}), \mathrm{Cu}(\mathrm{II}), \mathrm{Fe}(\mathrm{II}), \mathrm{Al}(\mathrm{III})$, and $\mathrm{Zn}$ (II) (50 ppm each) and the mixture was vigorously shaken for $1 \mathrm{~h}$ at room temperature. The resulting solid was separated by centrifugation $(7200 \mathrm{~g}, 10 \mathrm{~min})$ and the metal concentration in the supernatant was determined by ICP-AES. PA2 $(2.0 \mathrm{mg}, 6.4 \mu \mathrm{mol})$ was subsequently added to the supernatant $(5 \mathrm{~mL})$. After vigorous shaking for $3 \mathrm{~h}$ at room temperature, the mixture was centrifuged and the metal concentration in the supernatant determined by ICPAES.

\subsection{X-ray photoelectron spectroscopy (XPS) measurements}

To a $0.1 \mathrm{M} \mathrm{HCl}$ solution $(10 \mathrm{~mL})$ containing Pd(II) $(100 \mathrm{ppm})$ PA1 $(1.1 \mathrm{mg}, 4.7 \mu \mathrm{mol})$ was added and the mixture vigorously shaken for $1 \mathrm{~h}$ at room temperature. The resulting solid was collected by centrifugation $(7200 \mathrm{~g}, 10 \mathrm{~min})$ and dried at $80^{\circ} \mathrm{C}$ for $12 \mathrm{~h}$ under vacuum to yield the Pd-containing solid sample. In a similar manner, the Pt-containing solid sample was prepared using PA2 $(0.8 \mathrm{mg}, 2.6 \mu \mathrm{mol})$ and a $0.1 \mathrm{M} \mathrm{HCl}$ solution $(10 \mathrm{~mL})$ containing Pt(IV) (100 ppm). The resulting Pt- and Pd-containing solid samples were used for XPS measurements.

\subsection{Measurements}

${ }^{1} \mathrm{H}$ and ${ }^{13} \mathrm{C}$ NMR spectra were recorded using a JEOL JNM-ECX 500 NMR spectrometer. The metal concentrations were measured on an ICP-AES instrument (SPS5510, SII Nanotechnology Inc.). XPS measurements were conducted on an AXIS-ULTRA X-ray photoelectron spectrometer (Kratos Analytical Ltd.). The saturated concentrations of PA1 and PA2 in $0.1 \mathrm{M} \mathrm{HCl}$ were determined by $\mathrm{UV}$ absorption at $300 \mathrm{~nm}\left(\varepsilon=4.25 \times 10^{3}\right.$ and $7.55 \times 10^{3} \mathrm{M}^{-1} \mathrm{~cm}^{-1}$ for PA1 and PA2, respectively).

\section{RESULTS AND DISCUSSION}

\subsection{Synthesis of the precipitating agents}

$m$-Phenylene diamine-containing compounds (i.e., PA1 and PA2) were synthesized following the procedure described previously (Scheme 1) [14] and used as new precipitating agents for PGMs. PA1 and PA2 were obtained in high yields by condensation of aniline or 4-phenoxyaniline with 3,5-bis(trifluoroacetamido) benzoyl chloride followed by deprotection via transamidation with hydrazine. Remarkably, PA1 and PA2 were obtained in a one-pot process without tedious purification steps (e.g., column chromatography). The simple synthesis and purification used herein to prepare the precipitating agents are advantageous for practical use.

Figure 1 shows the ${ }^{1} \mathrm{H}$ NMR spectra of PA1 and PA2. The characteristic signals derived from the amine and amide protons were observed, and all the aromatic proton signals were well

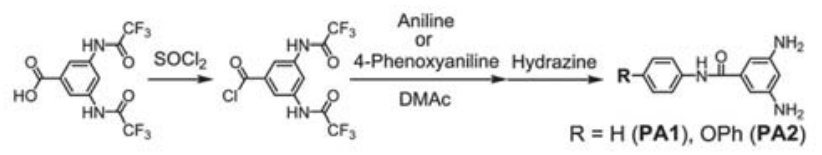

Scheme 1 Synthesis of $m$-phenylene diamine-containing agents. 


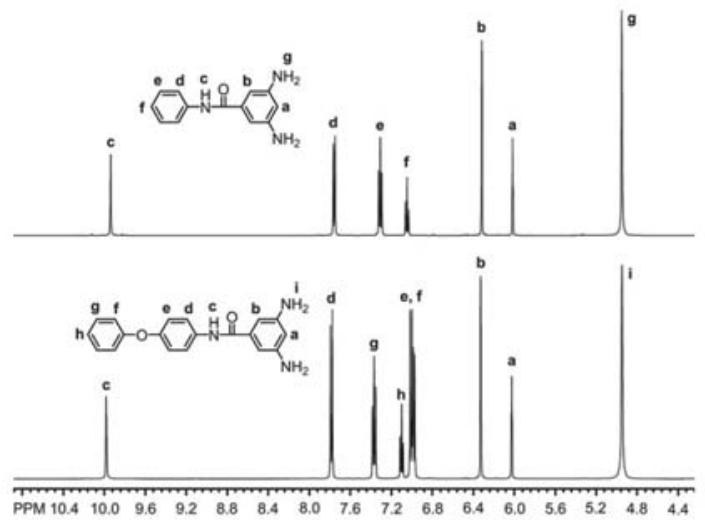

Figure $1{ }^{1} \mathrm{H}$ NMR spectra of PA1 and PA2 in DMSO- $d_{6}$.

assigned. In addition, the elemental analysis results supported the formation of the desired $m$-phenylene diamine-containing compounds. From these characterization data, we concluded that PA1 and PA2 were successfully synthesized.

PA1 and PA2 were soluble in polar aprotic solvents such as DMAc and dimethyl sulfoxide (DMSO) as well as in aqueous $\mathrm{HCl}$. The saturated concentrations of PA1 and PA2 in $0.1 \mathrm{M} \mathrm{HCl}$ at $20^{\circ} \mathrm{C}$ were 23.4 and $4.0 \mathrm{mg} / \mathrm{mL}$, respectively. Since the metal separation experiments were carried out at PA1 or PA2 concentrations in $0.1 \mathrm{M}$ $\mathrm{HCl}$ below $1.5 \mathrm{mg} / \mathrm{mL}$, these compounds were completely soluble in the metal-containing $\mathrm{HCl}$ solution at the initial stage.

\subsection{Precipitation behavior of $\mathrm{Pd}$ and $\mathrm{Pt}$}

The metal separation experiments using PA1 and PA2 were carried out as follows. To $0.1 \mathrm{M} \mathrm{HCl}$ solutions containing $\mathrm{Pd}(\mathrm{II})$ or Pt(IV) were added PA1 or PA2, and the resulting mixtures were vigorously shaken. In the separation experiments, $\mathrm{Pd}$ and $\mathrm{Pt}$ were precipitated out as solid mixtures of metals and precipitating agents. The precipitation percentages of $\mathrm{Pd}$ and $\mathrm{Pt}$ were determined by ICP-AES analysis of the supernatants after the removal of the precipitates. A precipitation percentage of $100 \%$ indicates that all the metals were precipitated out from the metal-containing solutions by attaching on the dissolved precipitating agents. Figures 2 and 3 show the relationship between the metal precipitation and the precipitating agent feed ratios. PA1 exclusively precipitated Pd under the studied conditions (Figures 2a and b). On the other hand, both Pd and Pt were precipitated using PA2 (Figures $3 \mathrm{a}$ and $\mathrm{b}$ ). Except in the case of Pt precipitation with PA1, the precipitation of Pd and Pt proportionally increased with the amount of the precipitating agents and reached $100 \%$ at ca. [precipitating agent]/
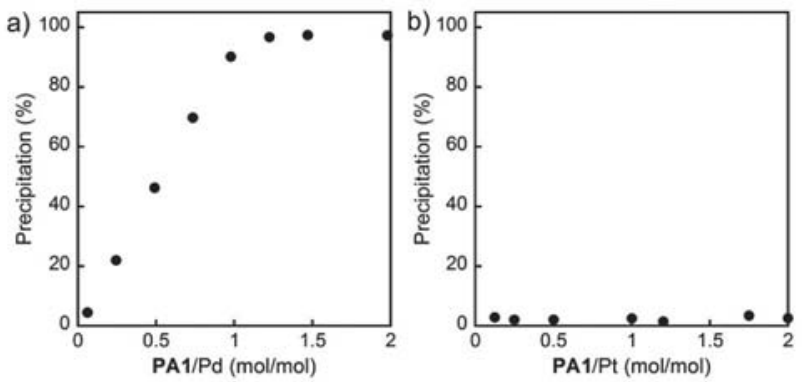

Figure 2 Effect of the PA1 loading on the precipitation of Pd (a) and Pt (b). Shaking time $=3 \mathrm{~h}$.
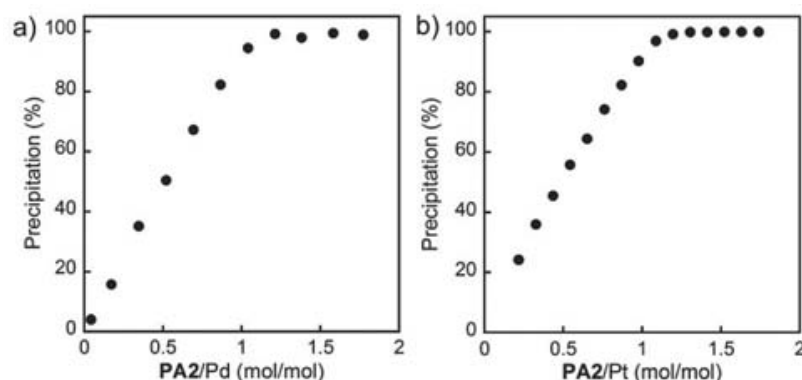

Figure 3 Effect of the PA2 loading on the precipitation of Pd (a) and Pt (b). Shaking time $=3 \mathrm{~h}$.
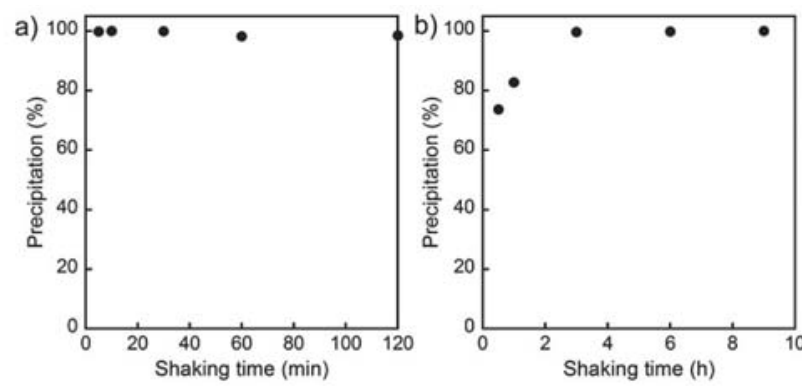

Figure 4 Effect of the shaking time on the precipitation of $\mathrm{Pd}(\mathrm{a})$ and $\mathrm{Pt}(\mathrm{b})$ using PA2. PA2 $/ \mathrm{Pd}=5 \mathrm{~mol} / \mathrm{mol}$ and $\mathbf{P A 2} / \mathrm{Pt}=5 \mathrm{~mol} / \mathrm{mol}$.

$[$ metal $]=1.0(\mathrm{~mol} / \mathrm{mol})$. This result clearly indicates that the precipitation of $\mathrm{Pd}$ and $\mathrm{Pt}$ were achieved via formation of metalcontaining precipitates composed of metals and precipitating agents in equimolar amounts.

Figure 4 shows the time-dependence of the precipitation at PA2 $/ \mathrm{metal}=5(\mathrm{~mol} / \mathrm{mol})$ in $0.1 \mathrm{M} \mathrm{HCl}$ solutions. Pd was rapidly precipitated (within $10 \mathrm{~min}$ ) with PA2. On the other hand, the precipitation of Pt with PA2 reached a plateau after $3 \mathrm{~h}$ of shaking. This result revealed that the Pd-containing precipitates formed faster as compared to the Pt-containing solids.

\subsection{Separation of Pd and Pt from base metals}

In actual recovery processes, it is significantly important to separate PGMs from base metals such as $\mathrm{Cu}, \mathrm{Fe}, \mathrm{Al}$, and $\mathrm{Zn}$ typically found in the leaching solution of scraps. The precipitation selectivities of $\mathrm{Pd}$ and $\mathrm{Pt}$ were examined using a $\mathrm{HCl}$ solution containing $\mathrm{Cu}(\mathrm{II}), \mathrm{Fe}(\mathrm{II}), \mathrm{Al}(\mathrm{III})$, and $\mathrm{Zn}$ (II) along with $\mathrm{Pd}(\mathrm{II})$ and Pt(IV). As shown in Table 1, PA1 and PA2 quantitatively precipitated Pd and/or Pt without dragging any of the base metals. It should be noted that the presence of the base metals produced no discernible impact on the precipitation behaviors of Pd and Pt. Thus, PA1 selectively precipitated Pd in contrast to PA2 that precipitated both Pd and Pt. Based on this result, we concluded that the precipitating agents used herein are feasible because of their high selectivity toward Pd and Pt in a base metal-containing solution.

\subsection{Mutual separation of $\mathrm{Pd}$ and $\mathrm{Pt}$}

Based on the precipitation results mentioned above, PA1 exclusively and selectively precipitated Pd, while PA2 precipitated both Pd and Pt. Therefore, we attempted to separately precipitate $\mathrm{Pd}$ and $\mathrm{Pt}$ from a $\mathrm{HCl}$ solution containing both $\mathrm{Pd}$ and $\mathrm{Pt}$ as well as base metals by using PA1 and PA2 in combination. First, selective 
Table 1 Precipitation of $\mathrm{Pd}$ and $\mathrm{Pt}$ from $\mathrm{HCl}$ solutions containing base metals.

\begin{tabular}{ccccccc}
\hline Precipitating & \multicolumn{6}{c}{ Precipitation (\%) } \\
\cline { 2 - 7 } agent & $\mathrm{Pd}(\mathrm{II})$ & $\mathrm{Pt}(\mathrm{IV})$ & $\mathrm{Cu}(\mathrm{II})$ & $\mathrm{Fe}(\mathrm{II})$ & $\mathrm{Al}(\mathrm{III})$ & $\mathrm{Zn}(\mathrm{II})$ \\
\hline PA1 & 94.6 & 3.4 & 0.8 & $<0.5$ & 0.8 & $<0.5$ \\
PA2 & 99.5 & 97.8 & 0.8 & $<0.5$ & $<0.5$ & $<0.5$ \\
\hline
\end{tabular}

Table 2 Mutual separation of $\mathrm{Pd}$ and $\mathrm{Pt}$ from a $\mathrm{HCl}$ solution containing base metals.

\begin{tabular}{ccccccc}
\hline Precipitation & \multicolumn{7}{c}{ Precipitation (\%) } \\
\cline { 2 - 7 } step & $\mathrm{Pd}(\mathrm{II})$ & $\mathrm{Pt}(\mathrm{IV})$ & $\mathrm{Cu}(\mathrm{II})$ & $\mathrm{Fe}(\mathrm{II})$ & $\mathrm{Al}(\mathrm{III})$ & $\mathrm{Zn}(\mathrm{II})$ \\
\hline 1st & 92.7 & 6.7 & $<0.5$ & $<0.5$ & $<0.5$ & $<0.5$ \\
2nd & 7.3 & 92.5 & $<0.5$ & $<0.5$ & $<0.5$ & $<0.5$ \\
\hline
\end{tabular}

Pd precipitation from a mixed solution containing Pd, Pt, and base metals in $0.1 \mathrm{M} \mathrm{HCl}$ was performed using PA1. After the removal of the Pd-containing precipitates, Pt precipitation from the residual solution was carried out with PA2. As a result, Pd and Pt were selectively and efficiently precipitated in the first $(92.7 \%$ for Pd and $6.7 \%$ for Pt) and second (7.8\% for Pd and $92.5 \%$ for Pt) steps, respectively (Table 2 ). This process was advantageous in that the mutual separation of Pd and Pt was achieved without the need for any other additives except for PA1 and PA2 and without changing the solution conditions (e.g., acid concentration).

\subsection{Study of the precipitation mechanism}

It is known that $\mathrm{Pd}(\mathrm{II})$ and $\mathrm{Pt}(\mathrm{IV})$ form chloro-complexes (i.e., $\left[\mathrm{PdCl}_{4}\right]^{2-}$ and $\left[\mathrm{PtCl}_{6}\right]^{2-}$ ) in aqueous $\mathrm{HCl}$ solutions $[15,16]$. The recovery mechanisms of metal chloro-complex anions are generally classified into two types: ligand-metal coordination and ion-pair formation. To discuss the recovery mechanism followed herein, we obtained the ${ }^{1} \mathrm{H}$ NMR spectra of PA1 in water and $0.1 \mathrm{M} \mathrm{HCl}$. The proton signals at 6.50 and $6.73 \mathrm{ppm}$ were assigned to the aromatic protons of the $m$-phenylene diamine moiety in water down-field shifted in $0.1 \mathrm{M} \mathrm{HCl}$ by 1.17 and $1.22 \mathrm{ppm}$, respectively (Figure 5). These down-field shifts indicate that the two amine groups in the precipitating agents were transformed into ammonium cations in $0.1 \mathrm{M} \mathrm{HCl}$. Since Pd, Pt, and the precipitating agents exist as ionic species under the studied conditions, an ion-pair formation mechanism between Pd and Pt chloro-complex anions and the precipitating agent cations was considered herein during the precipitation process. According to the data presented in Figures

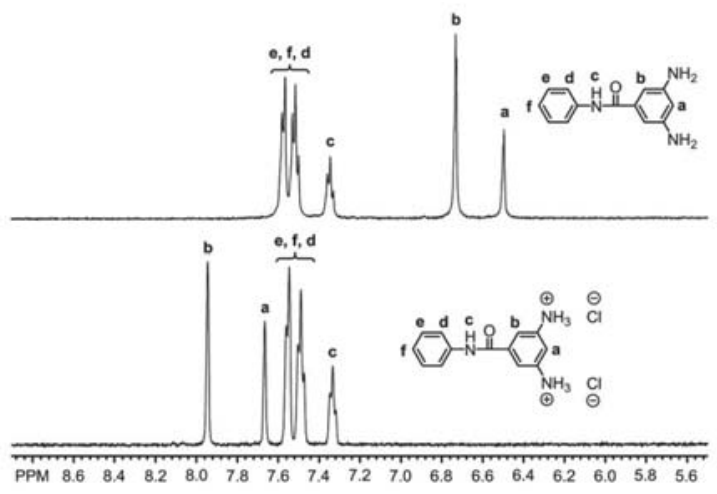

Figure $5 \quad{ }^{1} \mathrm{H}$ NMR spectra of PA1 in water and $0.1 \mathrm{M} \mathrm{HCl}$.
2 and 3, the ion-pairs formed in the precipitation process were composed of one metal chloro-complex and one precipitating agent molecule. The equimolar stoichiometry of the ion-pair components fulfilled the charge-balanced conditions (i.e., one divalent anion and two monovalent cations). The selective precipitation of Pd and Pt from base metals was also explained via ion-pair formation since the base metal cations cannot form ion-pairs with the precipitating agent cations.

We analyzed the metal-containing precipitates generated in the precipitation process by XPS measurements with the aim to confirm the ion-pair forms. Figure 6a shows the XPS spectrum of the precipitate composed of Pd and PA1. The characteristic $\mathrm{Pd} 3 \mathrm{~d}$ and N1s peaks were observed and the N/Pd atomic ratio was calculated to be 2.88. Similarly, the precipitate composed of $\mathrm{Pt}$ and PA2 showed the characteristic Pt4d and N1s peaks and a N/ Pt atomic ratio of 2.97 (Figure 6b). These XPS results strongly supported the formation of ion-pairs consisting of one metal chloro-complex anion and one precipitating agent molecule which contains three $\mathrm{N}$ atoms. Therefore, we concluded that $\mathrm{Pd}$ and/or Pt can be precipitated using PA1 and PA2 via formation of ion-pairs composed of metal chloro-complexes (i.e., divalent anions) and precipitating agents (i.e., divalent cations) in a 1:1 stoichiometric ratio (Figure 7).

Although PA2 achieved precipitation of both Pd and Pt, PA1 exclusively precipitated Pd under the same conditions. The difference between the two precipitating agents is hydrophobicity, which is derived from their chemical structures. Thus, PA1 is less hydrophobic than PA2 because of the lower number of hydrophobic aromatic rings. This difference in the hydrophobicity of PA1 and PA2 was also confirmed by the different saturated
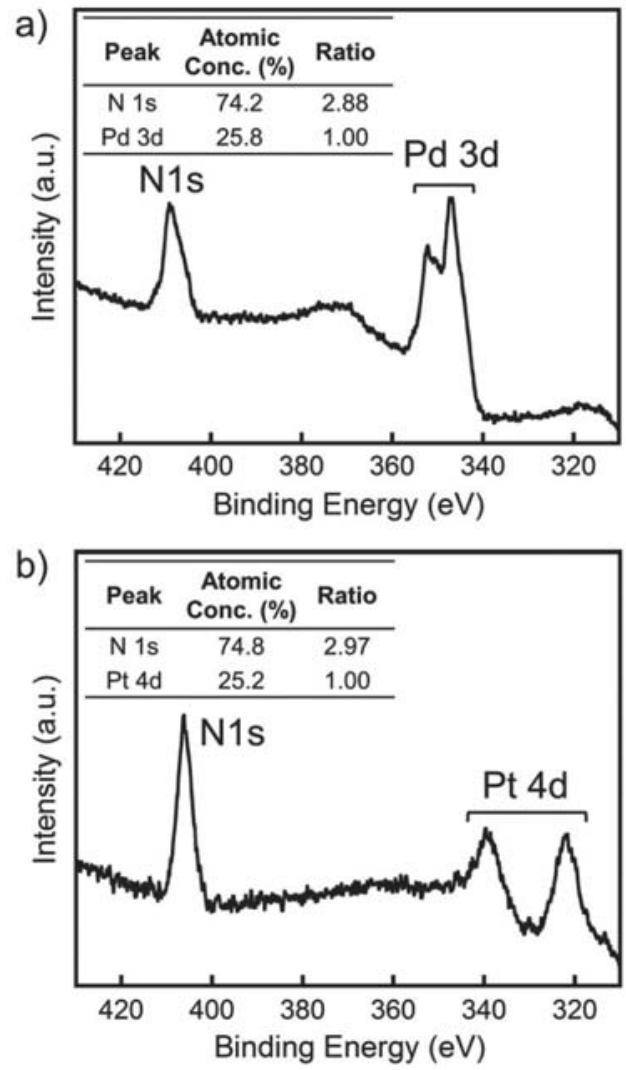

Figure 6 XPS spectra of Pd-containing (a) and Pt-containing (b) precipitates. 

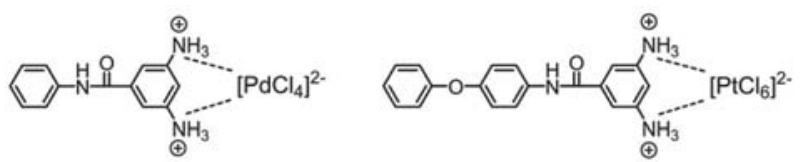

Figure 7 Proposed ion-pair structures composed of metal chloro-complex anions and precipitating agent cations.

concentrations in $0.1 \mathrm{M} \mathrm{HCl}$ of both agents. Thus, the solubility of PA1 $(23.4 \mathrm{mg} / \mathrm{mL})$ was higher than that of PA2 $(4.0 \mathrm{mg} / \mathrm{mL})$. The selective precipitation of Pd on PA1 can be explained in terms of the hydrophobicity of the Pt chloro-complex-PA1 ion-pair. Thus, the hydrophobicity of this ion-pair was not high enough to precipitate out of the $\mathrm{HCl}$ solution.

\section{CONCLUSION}

Two new precipitating agents, PA1 and PA2, were successfully prepared in a one-pot process with high yields. The precipitation of Pd and Pt were studied using PA1 and PA2 as metal precipitants. While PA1 exclusively precipitated $\mathrm{Pd}$ from a $\mathrm{HCl}$ solution containing Pd, Pt, and base metals, both Pd and Pt were precipitated from the same solution by using PA2. The precipitation tests performed by varying the loadings of the precipitating agents revealed that the metal-containing precipitates were composed of chloro-complex anions $\left(\left[\mathrm{PdCl}_{4}\right]^{2-}\right.$ or $\left.\left[\mathrm{PtCl}_{6}\right]^{2-}\right)$ and precipitating agents in equimolar amounts. The stoichiometric ratio of the ionpairs was in good agreement with the atomic ratios estimated by XPS. Since the precipitation mechanism followed herein was ionpair formation, the precipitating agent cations only precipitated chloro-complex anions of $\mathrm{Pd}$ and $\mathrm{Pt}$ in the absence of base metal cations. The different hydrophobicity of the precipitating agents allowed mutual separation of $\mathrm{Pd}$ and $\mathrm{Pt}$.

\section{References}

[1] Alonso, E., Field, F. R., Kirchain, R. E.; "Platinum availability for future automotive technologies", Environmental Science \& Technology, 46, 12986-12993 (2012).

[2] Khaliq, A., Rhamdhani, M. A., Brooks, G., Masood, S.; "Metal extraction processes for electronic waste and existing industrial routes: a review and Australian perspective", Resources, 3, 152-179 (2014).

[3] Hagelüken, C.; "Recycling the platinum group metals: A European perspective", Platinum Metals Review, 56, 29-35 (2012).

[4] Lokhande, T. N., Anuse, M. A., Chavan, M. B.; "Extraction and separation studies of platinum (IV) with N-n- octylaniline", Talanta, 47, 823-832 (1998).

[5] Lee, J. Y., Raju, B., Kumar, B. N., Kumar, J. R., Park, H. K., Reddy, B. R.; "Solvent extraction separation and recovery of palladium and platinum from chloride leach liquors of spent automobile catalyst", Separation and Purification Technology, 73, 213-218 (2010).

[6] Swain, B., Jeong, J., Kim, S. K., Lee, J. C.; “Separation of platinum and palladium from chloride solution by solvent extraction using Alamine 300", Hydrometallurgy, 104, 1-7 (2010).

[7] Gupta, B., Singh, I.; "Extraction and separation of platinum, palladium and rhodium using Cyanex 923 and their recovery from real samples", Hydrometallurgy, 134, 11-18 (2013).

[8] Jha, M. K., Gupta, D., Lee, J. C., Kumar, V., Jeong, J.; "Solvent extraction of platinum using amine based extractants in different solutions: A review", Hydrometallurgy, 142, 6069 (2014).

[9] Baba, Y., Eguchi, T., Inoue, K.; “Solvent extraction of palladium with dihexyl sulfide", Journal of Chemical Engineering of Japan, 19, 361-366 (1986).

[10] Ishimori, T., Watanabe, K., Nakamura, E.; "Inorganic extraction studies on the system between tri-n-butyl phosphate and hydrochloric acid", Bulletin of the Chemical Society of Japan, 33, 636-644 (1960).

[11] Bernardis, F. L., Grant, R. A., Sherrington, D. C.; “A review of methods of separation of the platinum-group metals through their chloro-complexes", Reactive and Functional Polymers, 65, 205-217 (2005).

[12] Rydberg, J., Cox, M., Musikas, C., Choppin, G.R.; "Solvent Extraction Principles and Practice, 2nd ed.", Marcel Dekker, Inc., pp. 480-505 (2004).

[13] Cleare, M. J., Charlesworth, P., Bryson, D. J.; "Solvent extraction in platinum group metal processing", Journal of Chemical Technology and Biotechnology, 29, 210-224 (1979).

[14] Matsumoto, K., Nishi, K., Ando, K., Jikei, M.; “Synthesis and properties of aromatic polyamide dendrimers with polyhedral oligomeric silsesquioxane cores", Polymer Chemistry, 6, 4758-4765 (2015).

[15] Levitin, G., Schmuckler, G.; "Solvent extraction of rhodium chloride from aqueous solutions and its separation from palladium and platinum", Reactive and Functional Polymers, 54, 149-154 (2003).

[16] Wang, C., Tong, Y., Huang, Y., Zhang, H., Yang, Y.; “Selone behavior towards palladium (II) extraction with hydrophobic ionic liquids and mechanism studies", RSC Advances, 5, 63087-63094 (2015). 